\title{
Prevalence and Predictors of Early Antenatal Booking Among Women of Reproductive Age in Tanzania: An Analysis of Data from the 2015-16 Tanzania HIV and Malaria Indicators Survey
}

Fabiola Vincent Moshi ( $\sim$ fabiola.moshi@gmail.com )

\section{Research}

Keywords: Antenatal booking, antenatal services, women of reproductive age

Posted Date: May 15th, 2020

DOl: https://doi.org/10.21203/rs.3.rs-28839/v1

License: (c) (1) This work is licensed under a Creative Commons Attribution 4.0 International License. Read Full License 


\section{Abstract}

Background: Early initiation of the antenatal clinic is vital as it allows early detection, management, and prevention of problems that may occur during pregnancy time. The aim of the analysis was to determine the prevalence and predictors of early antenatal booking among women of reproductive age in Tanzania.

Method: The study used data from the 2015-16 Tanzania HIV Demographic and Health Survey and Malaria Indicators Survey (2015-16 TDHS-MIS). A total of 6924 women of active reproductive age from 15 to 49 were included in the analysis. Both univariate and multiple regression analyses were used to determine predictors of early antenatal booking.

Results: Only $1586(22.9 \%)$ of pregnant women had early antenatal booking. After adjusted for the confounders, the predictors of early antenatal booking were age of a woman ( 20 to 34 years, AOR=1.554 at $95 \% \mathrm{Cl}=1.213-1.993$, and more than 34 years, $\mathrm{AOR}=1.758$ at $95 \% \mathrm{Cl}=1.306-2.368$ ); wealth status (rich, $\mathrm{AOR}=1.520$ at $95 \% \mathrm{Cl}=1.282-1.802$ ); education level (higher education, $\mathrm{AOR}=2.355$ at $95 \% \mathrm{Cl}=1.36$ 4.079); parity (Para 2 to $3, A O R=0.85$ at $95 \% \mathrm{Cl}=0.727-0.994$ and Para $5+, \mathrm{AOR}=0.577$ at $95 \% \mathrm{Cl}=0.465$ 0.715 ); zones (Unguja, $\mathrm{AOR}=0.433$ at $95 \% \mathrm{Cl}=0.284-0.658$ and $\mathrm{Pemba}, \mathrm{AOR}=0.392$ at $95 \% \mathrm{Cl}=0.236$ $0.649)$.

Conclusion: Early antenatal booking in Tanzania is extremely low. Women were more likely to initiate antenatal visits within the first 12 weeks are those from well-off families, those with higher education, primiparity women, and those from Tanzania mainland urban. The innovative interventional study is highly recommended in order to come up with an effective strategy to improve timing for antenatal booking

Plain English: Early antenatal booking is when a pregnant woman initiates antenatal visit for a checkup within the first 12 weeks of pregnancy. The study is about finding the percentage of women of reproductive age in Tanzania who made antenatal visits within the first 12 weeks of pregnancy. Early antenatal booking is beneficial to both pregnant women and unborn children. It is so because early visit does offer an opportunity for early detection of complications and prevention of complications.

The study also aimed to determine predictors of early antenatal booking in Tanzania. After review of literature socio-demographic characteristics of a woman were used to assess their influence on early antenatal booking. These characteristics were; the age of a woman, education status, wealth index, place of residence, marital status, working status, and zones within Tanzania. Also, the obstetric characteristic of a woman was used to assess its influence on early antenatal booking. In this characteristic, a parity of woman was used. The perception towards early antenatal booking was also included as a variable to assess its influence on early antenatal booking.

The Tanzania demographic and health survey 2015-16 data set was used to develop this manuscript. This study is of significance to both researches and policymakers. To researchers, the finding can guide the development of an intervention study or a program targeting to improve timing for antenatal visits. To 
policymakers, the finding can be used to guide the national guidelines for antenatal visits. It is quite clear that Tanzania is among the countries which offer folic acid supplement during the antenatal sessions. The supplement will be beneficial if it started to be given during the first 12 weeks of pregnancy.

\section{Introduction}

Maternal and neonatal morbidity and mortality remain to be a public health challenge worldwide. According to the World Health Organization (WHO) report of 2019, approximately 810 maternal death occurred every day in 2017[1] of which $94 \%$ occurred in middle and low-income countries. Also in the same year, 18 neonatal deaths occurred in every 1000 live birth worldwide. Tanzania is among the countries with the highest neonatal mortalities wherein 2017, 21 neonatal deaths occurred in every 1000 live births[2]. Most of these deaths are due to preventable causes.

For every maternal or neonatal death, there are several morbidities that can impair the quality of life of both mothers and children. Maternal morbidity refers to any physical or mental illnesses caused by pregnancy and/or childbirth[3] Some of these illnesses can even lead to long term mental and physical disabilities[3]. Severe Maternal Morbidity (SMM) can be defined as potentially life-threatening conditions that may occur during pregnancy, childbirth, or after the termination of pregnancy[4]. The indicators for SMM are the presence of hemorrhagic disorders, hypertensive disorders, and other systemic disorders caused by pregnancy and/or childbirth[4]. The highest burden of severe maternal morbidity is in subSaharan Africa which is as high as 198 per 1000 live births[5].

Neonatal health depends on the health status and nutritional status of their mothers and the health care these mothers receive during pregnancy, childbirth, and immediately after birth[6]. Neonatal health problems are prematurity, low birth weight, infection, jaundice, and asphyxia[7]. All of these health problems are preventable if invested in the health of a woman before pregnancy, during pregnancy, and during childbirth. A previous study done in Kenya found a significant relationship between inadequate antenatal services utilization and neonatal morbidities and mortalities[8]

It is globally accepted that the use of antenatal services remains to be a cornerstone of the reduction of maternal and neonatal morbidities and mortalities. In 2016 WHO came up with an antenatal model that aims to provide pregnant women with comprehensive care[9]. The model requires a pregnant woman to make at least one antenatal visit in the first trimester, two visits in the second trimester, and five visits in the third trimester[9]. In the visit the pregnant women to be counseled about healthy eating, and keeping physically active to stay healthy and prevent excessive weight gain during pregnancy; to be provided with an iron and folic acid supplementation in order to prevent maternal anemia, puerperal sepsis, low birth weight, and preterm birth[9]. Also to have a maternal and fetal assessment to rule out gestational diabetes mellitus, assess and counsel for tobacco cessation, assess and advise on alcohol cessation, counsel and test for HIV and provide ultra-sound services, full blood count testing to establish hemoglobin level, midstream urine culture for diagnosing asymptomatic bacteriuria, assess intimate partner violence, abdominal palpation[9]. 
The use of antenatal services is unacceptably low in developing countries including Tanzania. Despite the fact that $98 \%$ of a pregnant woman made at least one antenatal visits in Tanzania, only $51 \%$ had adequate antenatal visits[10]. A qualitative study done in Dar es Salaam Tanzania has pointed out factors which facilitate late booking for antenatal booking are individual perceptions about antenatal care, past experience with pregnancy, fear of early pregnancy disclosure, and socio-cultural beliefs[11]

Previous studies have linked early antenatal booking and adequate antenatal visits[12]. Early antenatal booking refers to the initiation of antenatal visits within the first three months of pregnancy. Early initiation of the antenatal clinic is of great importance as it allows early detection, managing, and prevents problems that occur during the pregnancy time[12]

Little is known on the predictors of early antenatal booking among women of reproductive age in Tanzania

\section{Methods}

\section{Study Area and period}

The study was conducted in the United Republic of Tanzania from August 22, 2015, through February 14, 2016. Tanzania is the largest country in East Africa which covers 940,000 square kilometers and 60,000 square kilometers is inland water. The country lies south of the equator and shares borders with eight countries: Kenya and Uganda to the North; Rwanda, Burundi, the Democratic Republic of Congo, and Zambia to the West; and Malawi and Mozambique to the South.

\section{Study design}

It was a national-based cross-sectional study utilizing the 2015-16 Tanzania Demographic and Health Survey and Malaria Indicator Survey (TDHS-MIS) dataset.

\section{Study population}

The study population was all women of reproductive age (aged 15-49 years). The study used Individual file recode (TZIR7BFL) with a total of 13266 women who responded to the survey ( $97 \%$ response rate). The study included all women who had birth within five years presiding the survey and a total of 7041 women were included in the study.

\section{Sampling Technique}

Two stages of sampling were used to obtain a sample for urban and rural areas in Tanzania Mainland and Zanzibar. In the first stage, a total of 608 clusters were selected and in the second stage, a 
systematic selection of households was involved. A total of 22 households were then systematically selected from each cluster, yielding a representative probability sample of 13,376 households for the 2015-16 TDHS-MIS. To enhance representativeness Tanzania was divided into nine geographic zones. Grouping the regions into zones was done to reduce sampling error by increasing the number of people in the denominator. The zone was western (Tabora and Kigoma regions), Northern zone (Kilimanjaro, Tanga, and Arusha), Central zone (Dodoma, Singida and Manyara), Southern Highland zone (Iringa, Njombe, and Iringa), Southern zone (Lindi and Mtwara), South West Highland zone (Mbeya Rukwa and Katavi), Lake zone (Kagera, Mwanza, Geita, Mara, Simiyu, and Shinyanga), Eastern zone (Dar es Salaam, Pwani, and Morogoro) and Zanzibar (Kaskazini Unguja, Kusini Unguja, Mjini Magharibi, Kaskazini Pemba and Kusini Pemba).

\section{Data Collection tool}

The 2015-16 TDHS-MIS used household questionnaires and individual questionnaires. These questionnaires based on the Measure DHS standard AIDS Indicator Survey and Malaria Indicator Survey questionnaires standards. They were adapted and modified to reflect the Tanzanian population. They were translated into Kiswahili, Tanzania's national language. The data presented in this study are from the individual questionnaire.

\section{Study variables}

Through a literature review, the conceptual framework was developed to guide the conceptualization (Fig. 1). The conceptual framework had primary independent variables (socio-demographic, obstetric characteristics of a woman and women's perception towards early booking), the outcome variable was antenatal booking. The outcome variable was a dummy variable coded as 1 if women had early antenatal booking and 0 if otherwise.

\section{Data Analysis}

Data were analyzed using IBM SPSS version 20 , started by describing all study variables using frequencies and percentages, and then assessed predictors of early antenatal booking. Binary logistic regression analysis was performed (univariate and multivariable) to determine predictors of early antenatal booking. All analyses were based at a $5 \%$ level of significance.

\section{Results}

\section{Socio-demographic Characteristics}

The study included 6924 women of reproductive age who had given birth within five years preceding the survey. Majority of study respondents $5113(73.8 \%)$ resided in the rural setting of Tanzania, aged 20 to 
34 years 4557(65.8\%), had primary education 4209(60.8) and were married 5650(86.1\%) Table 1 
Table 1

Socio-demographic Characteristics $(n=6924)$

\begin{tabular}{|c|c|c|}
\hline Variables & Frequency & Percent (\%) \\
\hline \multicolumn{3}{|l|}{ Place of residence } \\
\hline Urban & 1811 & 26.2 \\
\hline Rural & 5113 & 73.8 \\
\hline \multicolumn{3}{|l|}{ Age group } \\
\hline Less than 20 years & 541 & 7.8 \\
\hline 20 to 34 years & 4557 & 65.8 \\
\hline More than 34 years & 1826 & 26.4 \\
\hline \multicolumn{3}{|l|}{ Educational level } \\
\hline No education & 1329 & 19.2 \\
\hline Primary education & 4209 & 60.8 \\
\hline Secondary & 1326 & 19.2 \\
\hline Higher & 60 & 0.9 \\
\hline \multicolumn{3}{|l|}{ Parity } \\
\hline Para one & 1595 & 23 \\
\hline Para 2-4 & 3154 & 45.6 \\
\hline Para 5+ & 2175 & 31.4 \\
\hline \multicolumn{3}{|l|}{ Wealth index } \\
\hline Poor & 2734 & 39.5 \\
\hline Middle & 1363 & 19.7 \\
\hline Rich & 2827 & 40.8 \\
\hline \multicolumn{3}{|l|}{ Marital Status } \\
\hline Never in union & 441 & 6.4 \\
\hline Married & 5650 & 86.1 \\
\hline Widow & 119 & 1.7 \\
\hline Separated & 714 & 10.3 \\
\hline \multicolumn{3}{|c|}{ Respondent currently working } \\
\hline Not working & 1498 & 21.6 \\
\hline
\end{tabular}




\begin{tabular}{|lcl|}
\hline Variables & Frequency & Percent (\%) \\
\hline Working & 5426 & 78.4 \\
\hline Mainland/Zanzibar & & \\
Mainland urban & 1618 & 23.4 \\
Mainland rural & 4357 & 62.9 \\
Unguja (Zanzibar Island) & 594 & 8.6 \\
Pemba (Pemba Island) & 355 & 5.1 \\
Women perception towards early ANC booking & \\
\hline Positive & 6873 & 99.3 \\
Negative & 51 & 0.7 \\
\hline
\end{tabular}

\section{The relationship between socio-demographic characteristics and early antenatal booking}

Early antenatal booking had a significant relationship with the place of residence $(p<0.001)$, age group of a woman $(p<0.001)$, education level of a woman $(p<0.001)$, parity $(p<0.001)$, wealth index $(p<0.001)$ Table 2. 
Table 2

The relationship between socio-demographic characteristics and antenatal booking $(n=6924)$

\section{ANC Booking}

\begin{tabular}{|c|c|c|c|c|}
\hline Variables & Early & Late & $\mathrm{x} 2$ & $p$-value \\
\hline \multicolumn{5}{|l|}{ Place of residence } \\
\hline Urban & $527(29.1)$ & 1284(70.9) & & \\
\hline Rural & 1059(20.7) & 4054(79.3) & 53.283 & $<0.001$ \\
\hline \multicolumn{5}{|l|}{ Age group } \\
\hline Less than 20 years & 102(18.9) & $439(81.1)$ & & \\
\hline 20 to 34 years & 1109(24.3) & $3448(75.7)$ & & \\
\hline More than 34 years & $375(20.5)$ & 1451(79.5) & 16.113 & $<0.001$ \\
\hline \multicolumn{5}{|l|}{ Educational level } \\
\hline No education & 251(18.9) & 1078(81.1) & & \\
\hline Primary education & $979(23.3)$ & $3230(76.7)$ & & \\
\hline Secondary & $327(24.7)$ & $999(75.3)$ & & \\
\hline Higher & $29(48.3)$ & $31(51.7)$ & 36.737 & $<0.001$ \\
\hline \multicolumn{5}{|l|}{ Parity } \\
\hline Para one & $423(26.5)$ & 1172(73.5) & & \\
\hline Para 2-4 & $780(24.7)$ & 2374(75.3) & & \\
\hline Para 5+ & $383(17.6)$ & 1792(82.4) & 52.3 & $<0.001$ \\
\hline \multicolumn{5}{|l|}{ Wealth index } \\
\hline Poor & $520(19)$ & 2214(81) & & \\
\hline Middle & $290(21.3)_{-}$ & 1073(78.7) & & \\
\hline Rich & $776(27.4)$ & 2051(72.6) & 58.481 & $<0.001$ \\
\hline \multicolumn{5}{|l|}{ Marital Status } \\
\hline Never in union & 108(75.5) & $333(75.5)$ & & \\
\hline Married & $1260(22.3)$ & 4390(77.7) & & \\
\hline Widow & $32(26.9)$ & $87(73.1)$ & & \\
\hline Separated & 186(26.1) & $528(73.9)$ & 6.866 & 0.076 \\
\hline
\end{tabular}




\begin{tabular}{|lllll|}
\hline \multicolumn{5}{|c|}{ ANC Booking } \\
\hline Respondent currently working & & & & \\
\hline Not working & $341(22.8)$ & $1157(77.2)$ & & \\
\hline Working & $1245(22.9)$ & $4181(77.1)$ & 0.022 & 0.882 \\
\hline Mainland/Zanzibar & & & & \\
\hline Mainland urban & $496(30.7)$ & $1122(69.3)$ & & \\
\hline Mainland rural & $944(21.7)$ & $3413(78.3)$ & & \\
\hline Unguja (Zanzibar Island) & $99(16.7)$ & $495(83.3)$ & & \\
\hline Pemba (Pemba Island) & $47(13.2)$ & $308(86.8)$ & 90.691 & $<.001$ \\
\hline Women perception towards early ANC booking & & & & \\
\hline Positive & $1581(23)$ & $5292(77)$ & & \\
\hline Negative & $5(9.8)$ & $46(90.2)$ & 4.994 & 0.025 \\
\hline
\end{tabular}

\section{Predictors of early antenatal booking}

Predictors of early antenatal booking were age of a woman (20 to 34 years, $A O R=1.554$ at $95 \% \mathrm{Cl}=$ $1.213-1.993, p=0.001$ and more than 34 years, $A O R=1.758$ at $95 \% \mathrm{Cl}=1.306-2.368, p<0.001$ ); wealth status (rich, $\mathrm{AOR}=1.520$ at $95 \% \mathrm{Cl}=1.282-1.802, \mathrm{p}<0.001$ ); education level (higher education, $\mathrm{AOR}=$ 2.355 at $95 \% \mathrm{Cl}=1.36-4.079, \mathrm{p}=0.002$ ); parity (para 2 to $3, \mathrm{AOR}=0.85$ at $95 \% \mathrm{Cl}=0.727-0.994, \mathrm{p}=$ 0.041 , para $5+, \mathrm{AOR}=0.577$ at $95 \% \mathrm{Cl}=0.465-0.715, \mathrm{p}<0.001)$; zones (Unguja, $\mathrm{AOR}=0.433$ at $95 \% \mathrm{Cl}=$ $0.284-0.658, p<0.001$ and Pemba, $A O R=0.392$ at $95 \% \mathrm{Cl}=0.236-0.649, \mathrm{p}<0.001$ ) Table 3 
Table 3

Predictors of early antenatal booking among women of reproductive age in Tanzania( $\mathrm{n}=6924)$

\begin{tabular}{|c|c|c|c|c|c|c|c|c|}
\hline \multirow[t]{2}{*}{ Variable } & \multirow[t]{2}{*}{ OR } & \multicolumn{2}{|l|}{$95 \% \mathrm{Cl}$} & \multirow{2}{*}{$\begin{array}{l}\mathrm{p}- \\
\text { value }\end{array}$} & \multirow[t]{2}{*}{ AOR } & \multicolumn{2}{|l|}{$95 \% \mathrm{Cl}$} & \multirow[t]{2}{*}{ p-value } \\
\hline & & Lower & Upper & & & Lower & Upper & \\
\hline \multicolumn{9}{|l|}{ Age groups } \\
\hline Less than 20 years & 1 & & & & 1 & & & \\
\hline 20 to 34 years & 1.384 & 1.104 & 1.735 & 0.005 & 1.554 & 1.213 & 1.993 & 0.001 \\
\hline More than 34 years & 1.112 & 0.872 & 1.419 & 0.392 & 1.758 & 1.306 & 2.368 & $<0.001$ \\
\hline \multicolumn{9}{|l|}{ Place of residence } \\
\hline Urban & 1 & & & & 1 & & & \\
\hline Rural & 0.636 & 0.563 & 0.719 & $<001$ & 1.122 & 0.721 & 1.745 & 0.611 \\
\hline \multicolumn{9}{|l|}{ Wealth index } \\
\hline Poor & 1 & & & & 1 & & & \\
\hline Middle & 1.151 & 0.98 & 1.352 & 0.088 & 1.157 & 0.981 & 1.364 & 0.082 \\
\hline Rich & 1.611 & 1.42 & 1.828 & $\begin{array}{l}<.001 \\
0.0\end{array}$ & 1.520 & 1.282 & 1.802 & $<0.001$ \\
\hline \multicolumn{9}{|l|}{ Educational level } \\
\hline No education & 1 & & & & 1 & & & \\
\hline Primary education & 1.302 & 1.115 & 1.52 & 0.001 & 1.037 & 0.881 & 1.22 & 0.664 \\
\hline Secondary & 1.406 & 1.168 & 1.693 & $\begin{array}{l}< \\
0.001\end{array}$ & 1.018 & 0.818 & 1.266 & 0.873 \\
\hline Higher & 4.018 & 2.378 & 6.789 & $\begin{array}{l}< \\
0.001\end{array}$ & 2.355 & 1.36 & 4.079 & 0.002 \\
\hline \multicolumn{9}{|l|}{ Parity } \\
\hline Para one & 1 & & & & & & & \\
\hline Para 2-4 & 0.91 & 0.793 & 1.045 & 0.18 & 0.85 & 0.727 & 0.994 & 0.041 \\
\hline Para 5+ & 0.592 & 0.506 & 0.693 & $\begin{array}{l}< \\
0.001\end{array}$ & 0.577 & 0.465 & 0.715 & $<0.001$ \\
\hline \multicolumn{9}{|l|}{ Mainland/Zanzibar } \\
\hline Mainland urban & 1 & & & & 1 & & & \\
\hline Mainland rural & 0.626 & 0.551 & 0.711 & $\begin{array}{l}<.001 \\
0\end{array}$ & 0.807 & 0.507 & 1.284 & 0.365 \\
\hline
\end{tabular}




\begin{tabular}{|c|c|c|c|c|c|c|c|c|}
\hline \multirow[t]{2}{*}{ Variable } & \multirow[t]{2}{*}{ OR } & \multicolumn{2}{|l|}{$95 \% \mathrm{Cl}$} & \multirow{2}{*}{$\begin{array}{l}\mathrm{p}- \\
\text { value }\end{array}$} & \multirow[t]{2}{*}{ AOR } & \multicolumn{2}{|l|}{$95 \% \mathrm{Cl}$} & \multirow[t]{2}{*}{ p-value } \\
\hline & & Lower & Upper & & & Lower & Upper & \\
\hline $\begin{array}{l}\text { Unguja (Zanzibar } \\
\text { Island) }\end{array}$ & 0.452 & 0.356 & 0.575 & $<.001$ & 0.433 & 0.284 & 0.658 & $<0.001$ \\
\hline Pemba (Pemba Island) & 0.345 & 0.25 & 0.478 & $<.001$ & 0.392 & 0.236 & 0.649 & $<0.001$ \\
\hline \multicolumn{9}{|c|}{ Women perception towards early ANC booking } \\
\hline Positive & 1 & & & & 1 & & & \\
\hline Negative & 0.364 & 0.144 & 0.917 & 0.032 & 0.444 & 0.175 & 1.124 & 0.086 \\
\hline
\end{tabular}

\section{Discussion}

Despite the fact that early antenatal booking provides early detection, management, and prevention of problems that may occur during pregnancy time, the prevalence of early antenatal initiation in Tanzania is extremely low (22.9\%). The WHO has recommended folic acid supplementation as early as possible in pregnancy to prevent neural tube defects [13]. The first 12 weeks of pregnancy is a vital period for a neonate when the organogenesis is taking place. It is a critical time when the folic acid supplementation is needed. The folic acid supplementation is highly needed in low resources countries like Tanzania where women become pregnant while anemic and with micronutrient deficient

A bit higher prevalence was reported in similar studies done elsewhere in Africa[14-16]. The observed difference could be due to the differences in the sample size involved and the criterion used to categorize early booking. Why this study used population-based data with a large sample size, other studies used small samples. Also, the criteria used to categorize early booking differ; early booking in this study was antenatal visit within twelve weeks while other studies went as far as 16 weeks and 20 weeks. The controversy on early antenatal booking is now cleared with the release of a new model for antenatal attendance by the World Health Organization. The new model stipulates clearly that the first antenatal booking should be made within the first 12 weeks of pregnancy[9].

This study found that one of the predictors of early antenatal booking was the age of the pregnant woman. The likelihood of initiating antenatal visits early increased with an increase in age. Pregnant women who were aged 20 to 34 years were 1.5 times more likely to initiate antenatal visits early compare to pregnant women who were aged less than 20 years. Also, those aged 35 years and above were 1.7 times more likely to have an early antenatal booking. This is a surprising finding because it is expected that younger women are inexperienced and are in their first pregnancies could book earlier than older women. The possible explanation could be they are afraid to reveal their pregnancy status early something which could be dangerous to them. Deliberate effort to sensitize pregnant women on early antenatal booking is highly recommended with needful attention to young women. The different finding was reported by a previous study done in Ethiopia which showed older women were 3 times more likely to 
initiate antenatal visit late compared to younger women[17]. The difference could be due to different study populations.

The study also found that level of education of pregnant women significantly influenced the antenatal initiation. Pregnant women with higher education were 2.4 more likely to initiate antenatal early compared to those with no formal education. Formal education could have exposed them to healthrelated information and sensitize them on maternal services utilization. It is recommended that the health information provided in antenatal sessions focus more on illiterate women in order to sensitize them to use maternal services. Similar studies have reported similar findings[14, 18]

The parity of a woman also significantly influenced antenatal initiation. Pregnant women of higher parity were less likely to initiate antenatal sessions early. The likelihood decreased as the parity increased. Pregnant women of 2 to three parity were $15 \%$ less likely to initiate antenatal visits early when compared to primipara and those with 5 and more children were $42.3 \%$ less likely to initiate antenatal visits with the first 12 weeks of pregnancy. Similar findings were reported by similar previous studies[18, 19]. Pregnant women of high parity are most likely to have low-risk perception towards pregnancy and childbirth[20]. The low-risk perception could be influenced by uneventful previous childbirth. This is worrisome because each pregnancy can develop serious complications. The study recommends for needful effort on sensitizing multiparity women on risks associated with pregnancy and childbirth. Previous studies have reported that pregnant women with previous complications are more likely to initiate antenatal clinic early if compared with those without complications.

The study also found a significant relationship between antenatal initiation and wealth status. Pregnant women from rich families were 1.5 times more likely to initiate antenatal clinic early if compared to pregnant women from poor families. Antenatal services in Tanzania are offered for free but there are hidden costs that pregnant women and her family have to incur in order to receive the service. Costs like transport costs. This is evidenced by a previous study that found a significant association between early initiations of antenatal clinics and distance to a nearby health facility[15]. The longer the distance the higher the transport cost.

Pregnant women from Zanzibar islands were significantly less likely to initiate antenatal booking early if compared to pregnant women in mainland urban. Those from Unguja Island were $56.7 \%$ less likely to initiate antenatal clinics early if compared to pregnant women from mainland urban. Pregnant women from Pemba Island were $60.8 \%$ less likely to initiate antenatal clinics early if compared with pregnant women from mainland urban. Pregnant women from mainland rural were $19.3 \%$ less likely to initiate antenatal clinics early compared to mainland urban but the difference was not statistically significant. The study recommends targeted effort to improve early initiation of antenatal visits to Tanzania Islands where the majority of women book for antenatal visits late.

\section{Conclusion}


Early antenatal booking in Tanzania is extremely low. Women are less likely to initiate antenatal visits within the first 12 weeks are those from poor families, of low education, high parity, and from Zanzibar Islands. The innovative interventional study is highly recommended in order to come up with an effective strategy to improve timing for antenatal booking

\section{Declarations}

\section{Ethics approval and consent to participate}

Data collection and the survey content and protocol were approved by Tanzania's National Institute for Medical Research (NIMR), the Zanzibar Medical Ethics and Research Committee (ZAMREC), the Institutional Review Board of ICF International, and the Centers for Disease Control and Prevention in Atlanta, USA. Participants provided verbal consents and the household interviews took place at the private condition. Participants who were under 18 years old written consent were requested from their parents or guardians.

\section{Consent for publication}

Not applicable

\section{Availability of data and material}

The data that support this analysis are available from the 2015-16 Tanzania HIV and Malaria Indicators Survey (THMIS). This survey was conducted by the National Bureau of Statistics (NBS) in collaboration with the Tanzania Commission for AIDS (TACAIDS) and the Zanzibar AIDS Commission (ZAC), the Ministry of Health, Community Development, Gender, Elderly and Children (MoHCDEC) (Tanzania) and the USAID-Funded Measure DHS project. Data is available from the authors upon reasonable request and with permission from MEASURE DHS

\section{Competing interests}

The author declares there is no competing interest

\section{Funding}

The study was not funded

\section{Acknowledgments}


The author is grateful to MEASURE DHS for providing them with the data set.

\section{Authors' contributions}

FVM did data analysis and drafted introduction, the method, results, and discussion. I also did a critical review of the manuscript before submission.

\section{Availability of data and materials}

Data set is available and can be shared on request

\section{References}

1. WHO. Maternal mortality Evidence brief. Matern Mortal [Internet]. 2019;(1):1-4. Available from: https://apps.who.int/iris/bitstream/handle/10665/329886/WHO-RHR-19.20-eng.pdf?ua=1

2. WHO. World Health Statistics 2019: Monitoring Health for the SDG [Internet]. Vol. 1, Duke Law Journal. 2019. 1-13 p. Available from: https://apps.who.int/iris/bitstream/handle/10665/324835/9789241565707-eng.pdf

3. Koblinsky M, Chowdhury ME, Moran A, Ronsmans C. Maternal morbidity and disability and their consequences: Neglected agenda in maternal health. J Heal Popul Nutr. 2012;30(2):124-30.

4. Woldeyes WS, Asefa D, Muleta G. Incidence and determinants of severe maternal outcome in Jimma University teaching hospital, south-West Ethiopia: A prospective cross-sectional study. BMC Pregnancy Childbirth. 2018;18(1):1-12.

5. Geller SE, Koch AR, Garland CE, MacDonald EJ, Storey F, Lawton B. A global view of severe maternal morbidity: Moving beyond maternal mortality. Reprod Health. 2018;15(Suppl 1).

6. Woldeamanuel GG, Geta TG, Mohammed TP, Shuba MB, Bafa TA. Effect of nutritional status of pregnant women on birth weight of newborns at Butajira Referral Hospital, Butajira, Ethiopia. SAGE Open Med. 2019;7:205031211982709.

7. Papadopoulos T, Abrahim A, Sergelidis D, Bitchava K. Original article Epєuvпtıкń. 2011; (January):119-23.

8. Arunda M, Emmelin A, Asamoah BO. Effectiveness of antenatal care services in reducing neonatal mortality in Kenya: Analysis of national survey data. Glob Health Action [Internet]. 2017;10(1). Available from: https://doi.org/10.1080/16549716.2017.1328796

9. World Health Organization (WHO). WHO Recommendations on Antenatal Care for a Positive Pregnancy Experience: Summary. World Heal Organ [Internet]. 2018;10(January):1-10. Available from: http://apps.who.int/iris/bitstream/handle/10665/259946/WHO-RHR-18.01eng.pdf;jsessionid=A4152E9CECB885109A6D3AC066FC63A3? sequence=1\%0Ahttp://apps. who.int/iris/bitstream/10665/259946/1/WHO-RHR-18.01-eng.pdf 
10. Ministry of Health, Community Development, Gender, Elderly and Children (MoHCDGEC) [Tanzania Mainland], Ministry of Health (MoH) [Zanzibar], National Bureau of Statistics (NBS), Office of the Chief Government Statistician (OCGS) and I. Tanzania Demographic and Health Survey and Malaria Indicator Survey 2015-2016 [Internet]. Tanzania Demographic and Health Survey and Malaria Indicator Survey (TDHS-MIS) 2015-16. Dar es Salaam, Tanzania, and Rockville, Maryland, USA; 2016. Available from: https://www.dhsprogram.com/pubs/pdf/FR321/FR321.pdf

11. Mgata S, Maluka SO. Factors for late initiation of antenatal care in Dar es Salaam, Tanzania: A qualitative study. BMC Pregnancy Childbirth. 2019;19(1):415.

12. Belayneh T, Adefris M, Andargie G. Previous early antenatal service utilization improves timely booking: Cross-sectional study at university of Gondar Hospital, northwest Ethiopia. J Pregnancy. 2014;2014.

13. WHO. WHO Recommendation on Antenatal Care for a Positive Pregnancy Experience. 2016;368. Available from: https://apps.who.int/iris/bitstream/handle/10665/250796/9789241549912eng.pdf;jsessionid=6CB754F51404AB2FCE13F3F4E23AFF88? sequence $=1$

14. Fisseha G, Miruts G, Tekie M, Michael AW, Yemane D, Gerezigiher T. Predictors of Timing of First Antenatal Care Booking at Public Health Centers in Mekelle City , Northern Ethiopia. 2015;3(3):55-60.

15. Twg TWG. Proportion and Factors Associated with late Antenatal Care Booking among Pregnant Mothers in Gondar Town , North West Ethiopia. 2015;19(June):94-100.

16. Tolefac PN, Halle-ekane GE, Agbor VN, Sama CB, Ngwasiri C, Tebeu PM. Why do pregnant women present late for their first antenatal care consultation in Cameroon? 2017;1-6.

17. Tekelab T, Berhanu B. Original Research Factors Associated with Late Initiation of Antenatal Care among Pregnant Women Attending Antenatal Clinic at Public Health Centers in. 2014;7522(April):108-15.

18. Hussein K, Mannekulih E. Trend and barriers of antenatal care utilization from 2000 to 2016 Ethiopian DHS: A data mining approach. 2019;3.

19. Gross K, Alba S, Glass TR, Schellenberg JA, Obrist B. Timing of antenatal care for adolescent and adult pregnant women in south-eastern Tanzania. 2012;

20. Moshi F, Nyamhanga T. Understanding the preference for homebirth; an exploration of key barriers to facility delivery in rural Tanzania. Reprod Health [Internet]. 2017;14(1):132. Available from: http://reproductive-health-journal.biomedcentral.com/articles/10.1186/s12978-017-0397-z

\section{Figures}




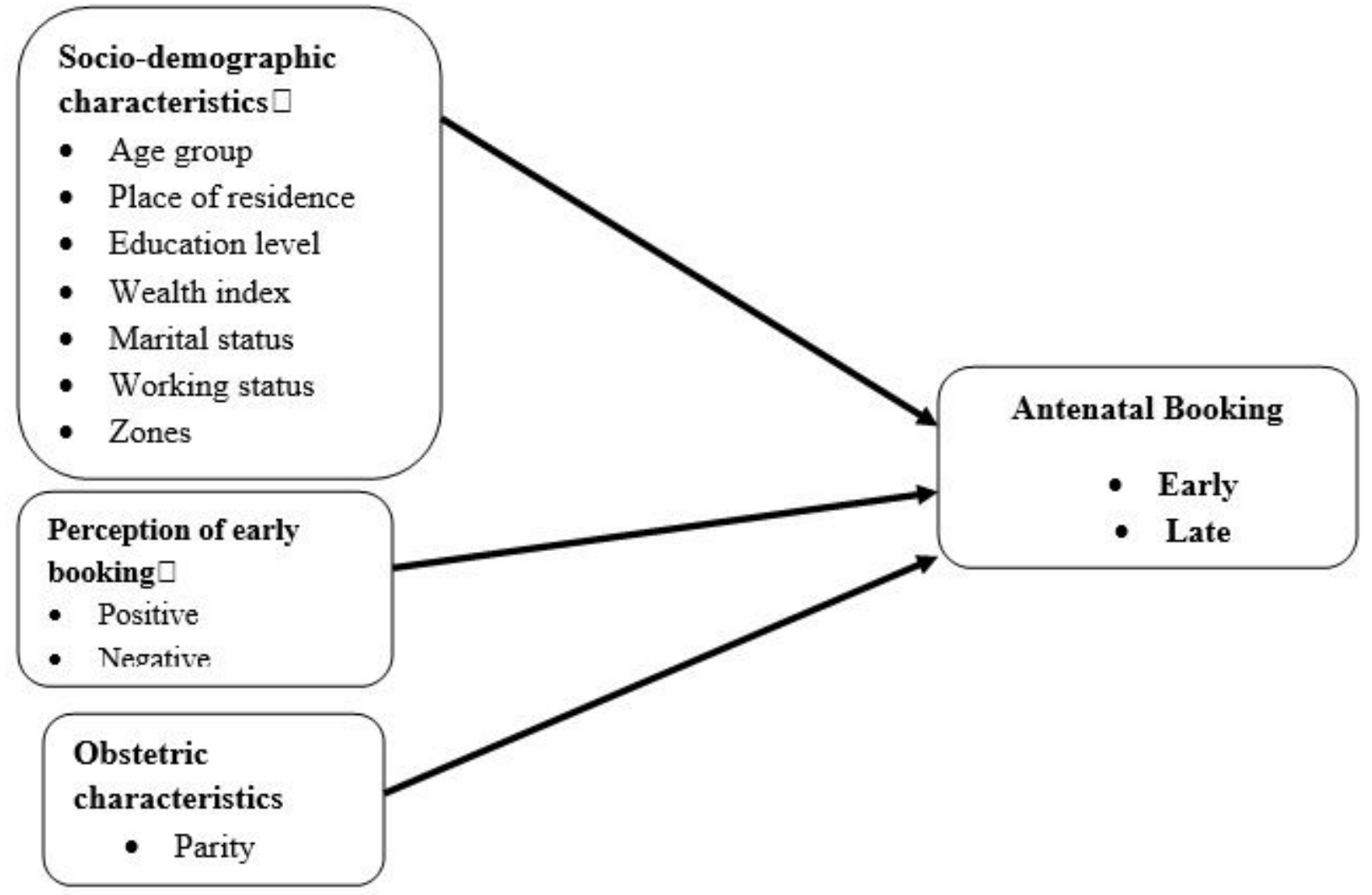

Figure 1

Conceptual framework predictors of early antenatal booking and its influence on antenatal services utilization 